\title{
Anti-Termite Activity of Melia azedarach Extracts
}

\author{
Yanico Hadi Prayogo ${ }^{1}$, Romi Irka Putra ${ }^{1}$, Izza Firdausi Hadiyanto ${ }^{1}$, Evie Nihayah ${ }^{1}$, Wasrin Syafii ${ }^{1, *}$, Rita \\ Kartika Sari ${ }^{1}$, Irmanida Batubara ${ }^{2,3}$ \\ ${ }^{1}$ Department of Forest Products, Faculty of Forestry and Environment, IPB University. Kampus IPB Darmaga, 16680, Bogor, \\ Indonesia \\ ${ }^{2}$ Department of Chemistry, Faculty of Mathematics and Natural Sciences, IPB University. Kampus IPB Darmaga, 16680, Bogor, \\ Indonesia \\ ${ }^{3}$ Tropical Biopharmaceutical Study Center, IPB University. Kampus IPB Darmaga, 16680, Bogor, Indonesia \\ * Corresponding Author. E-mail address: wasrinsy@apps.ipb.ac.id
}

\section{ARTICLE HISTORY:}

Received: 7 September 2021

Peer review completed: 24 November 2021 Received in revised form: 30 November 2021 Accepted: 7 December 2021

\section{KEYWORDS:}

Anti-termite

Bioactive compound

Melia azedarach

Natural preservative
C 2022 The Author(s). Published by Department of Forestry, Faculty of Agriculture, University of Lampung in collaboration with Indonesia Network for Agroforestry Education (INAFE). This is an open access article under the CC BY-NC license:

https://creativecommons.org/licenses/by$\mathrm{nc} / 4.0 \%$

\begin{abstract}
Natural preservatives have been widely considered as non-synthetic materials that can prevent the biodegradation of wood due to subterranean termite attacks, namely Coptotermes curvignathus. Melia azedarach is a fast-growing species that has been widely studied for its antifeedant compounds and shows good potential to be developed as a biopesticide, especially as an anti-termite. This study aimed to identify the termicide and antifeedant properties of the wood, leaves, and bark extracts of Melia azedarach against subterranean termites and identify their bioactive compounds. The acetone extract from the three parts of the tree was fractionated. The most active fractions were selected from each part based on the percentage of termite mortality and antifeedant activity and analyzed for its bioactive compounds by pyrolysis GCMS. The ethyl acetate fraction of Melia azedarach bark exhibited strong toxic properties compared to other fractions. In the leaf section, the diethyl ether fraction showed the best termite repellent (antifeedant) properties. The anti-termite properties influenced phenolic compounds and organic acid that dominated the bark ethyl acetate fraction and leaf diethyl ether fraction. These findings show the great potential of bioactive compounds from biomaterials to be developed as a promising biopesticide.
\end{abstract}

\section{Introduction}

Most of the wood preservatives used today are synthetic preservatives that negatively affect the environment and human health. Wang et al. (2021) reported that commercial wood preservatives such as 2.4-dichlorophenol and 2.4.6-trichlorophenol have been shown to cause cancer. Likewise, water that has been contaminated and washed by wood preservatives had a high level of toxicity to aquatic biota (Łebkowska et al. 2003). Natural compounds with a better level of safety and the same effectiveness of preservation as a substitute for synthetic preservatives should be developed to overcome these requirements.

One of the wood preservation purposes is to prevent wood damage caused by microorganisms and insects, including wood-destroying termites. Coptotermes curvignathus is one of the termites with a very high level of attack on lignocellulosic materials (Nandika et al. 2003). Termites can attack the various lignocellulosic materials in buildings in Indonesia and cause 
economic losses reaching approximately IDR 8.67 trillion per year (Nandika 2015). Several studies have shown the efficacy of secondary metabolites from plants against termite attacks, including the extracts, fractions, and isolates of leaf compounds of Protium javanicum (Adfa et al. 2010), the resin of Dacryodes edilus (Bédounguindzi et al. 2020), extracts of the heartwood of Hymenaea stigonocarpa (Maranhão et al. 2013), and extracts of the bark and leaves of Lawsonia inermis (Adedeji et al. 2017). Therefore, it can be considered that the compounds and isolates of plant metabolites have good properties as substitute materials for synthetic preservatives to overcome economic problems due to termite attacks.

Melia azedarach is a fast-growing tree species that is extensively produced in Indonesia. Statistics Indonesia (2019) reported that Melia azedarach tree log production in 2019 was 15,995 $\mathrm{m}^{3}$. Research using extracts, fractions, or components of compounds from this plant shows good potential as a biopesticide. For example, methanol extracts from Melia azedarach leaf and seeds showed a biopesticide effect against the destroying insect of Hyblaea puera (Nathan and Sehoon 2006). In addition, extracts from Melia azedarach fruit have potential as nematicides (Cavoski et al. 2012), parasitoid-related biopesticides (Defagó et al. 2011), and larvicides (Al-Mehmadi and Al-Khalaf 2010).

As mentioned above, Melia azedarach could be promising as a substitute material for synthetic preservatives. In particular, the leaf extract of Melia azedarach was toxic to the Microtermes obesi and Odontotermes obesus termite species (Qureshi et al. 2015). However, there is still no information on studies that reported the potential of the extracts of the heartwood and bark of Melia azedarach from Indonesia as an anti-termite C. curvignathus. To date, there have also been no studies on identifying the components of Melia azedarach's bioactive compounds as an anti-termite. Therefore, this study was conducted to determine the potential of Melia azedarach trees from Indonesia in inhibiting the activity of subterranean termites and identify the bioactive components in the most active fractions.

\section{Materials and Methods}

\subsection{Materials}

A 6-years old Melia azedarach tree was obtained from the Cibeureum area, Bogor, Indonesia. The leaves, bark, and heartwood were separated and converted to a powder. The test termites were Coptotermes curvignathus, obtained from Kawasan Hutan Dengan Tujuan Khusus (KHDTK) Yanlapa, Bogor, Indonesia. The chemicals used were acetone, n-hexane, diethyl ether, ethyl acetate, $70 \%$ ethanol, distilled water, filter paper, dental cement, tissue, and cellulose paper.

\subsection{Methods}

\subsubsection{Extraction and fractionation}

A total of $2 \mathrm{~kg}$ of leaf, bark, and heartwood powders were immersed in acetone with a powder-solvent ratio of 1:3. The mixture was allowed to stand for $48 \mathrm{~h}$ and then filtered to obtain a separate filtrate. This process was repeated until a clear filtrate was obtained. The filtrate was concentrated using a rotary evaporator (Heidolph, Germany), producing a concentrated extract. The extract was weighed to obtain the yield of the extract. The extracts were then fractionated using n-hexane, diethyl ether, and ethyl acetate (Fig. 1) to obtain the hexane soluble fraction (HF), 
diethyl ether soluble fraction (DF), ethyl acetate soluble fraction (EF), and water soluble fraction (WF). The yield of the fraction was measured against the initial weight of the powder.

Acetone extract (dissolved in water)

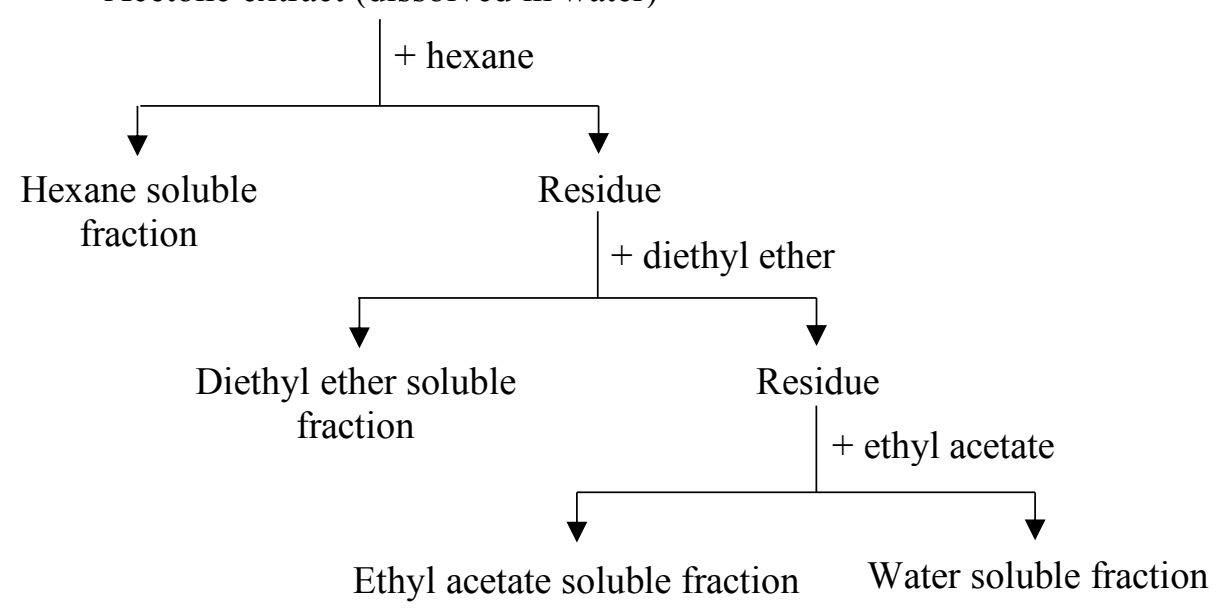

Fig. 1. Fractionation process of the extract of Melia azedarach's leaf, bark, and heartwood.

\subsubsection{Anti-termite test}

The anti-termite test was performed using the cellulose paper method (Mukai et al. 2017). The test determined the termiticidal (termite mortality) and antifeedant activity (the weight loss of cellulose paper after the test). Cellulose paper (Whatman 42, $1.5 \mathrm{~cm}$ in diameter) was oven-dried at $103 \pm 2{ }^{\circ} \mathrm{C}$ for $24 \mathrm{~h}$ and then weighed. The cellulose paper was then soaked with fractions with concentrations of $2,4,6,8$, and $10 \%(\mathrm{w} / \mathrm{w})$. The control group was also made by soaking cellulose paper with and without acetone. Each test group consisted of three papers for three replications. The preparation of the anti-termite test is presented in Fig. 2.

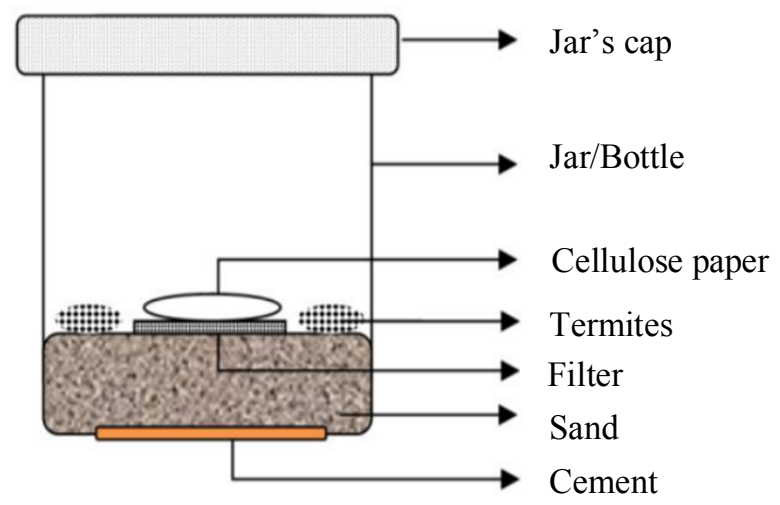

Fig. 2. Anti-termite test preparation.

Cellulose paper treated with and without fractions was placed in glass jars. A total of 50 termites consisting of 45 workers and 5 soldiers were used for testing. The test was performed for 21 days in a dark room. After 21 days, the termiticidal activity was measured using equation 1 and the antifeedant activity was calculated using equation 2 .

$$
M=\left(\frac{I_{0}-I}{I_{0}} \times 100 \%\right)-M c
$$


where $M$ is mortality (\%), $M c$ is the mortality percentage of the control group ( $\%), I_{o}$ is the initial number of alive termites (individual), and $I$ is the number of alive termites after 21 days of treatment (individual).

$$
W L=\left(\frac{W 0-W}{W 0}\right) \times 100 \%
$$

where $W L$ is cellulose paper weight loss $(\%), W_{0}$ is the initial weight of cellulose paper $(\mathrm{g})$, and $\mathrm{W}$ is the weight of cellulose paper after 21 days of treatment $(\mathrm{g})$.

The results were reported as the relationship of concentration to the percentage of termite mortality and feed activity. The $\mathrm{LC}_{50}$ value (concentration value that causes the death of individual termites by $50 \%$ of the total individual) was also analyzed using probit analysis.

\subsubsection{Identification of compounds by Py-GCMS}

The best fractions from leaf, bark, and heartwood were selected as three fractions with the highest mortality percentage and the best antifeedant activity. The compound analysis was conducted using a pyrolysis gas chromatography-mass spectrometry (Py-GCMS) type QP2010 (Shimadzu, Japan). The pyrolysis temperature used was $400^{\circ} \mathrm{C}$ for $1 \mathrm{~h}$. The injected temperature was $280^{\circ} \mathrm{C}$ and the column temperature was gradually conducted from $50-280^{\circ} \mathrm{C}$ with a heating rate of $15^{\circ} \mathrm{C} / \mathrm{min}$. Electrospray ionization (mass range of $15-1000 \mathrm{~m} / \mathrm{z}$ ) was used as the ionization mode, and the weight analyzer was performed by a high-performance quadrupole mass analyzer. The resulting mass fragmentation was identified using the National Institute of Standards and Technology (NIST) database to obtain the type of compound.

\subsubsection{Statistical analysis}

Data related to mortality and weights of cellulose paper were presented in the average of three replications using the 2016 Microsoft Excel. In addition, probit analysis was also analyzed using the same application as the probit value table guidelines (Finney and Stevens 1948).

\section{Results and Discussion}

\subsection{The Yield of Acetone Extract and Its Fraction}

Extraction yields in each section of leaf, bark, and heartwood showed various levels of secondary metabolite or extractive components in each section and fraction. Melia azedarach leaf extract showed the highest yield percentage compared to bark and heartwood (Table 1).

Table 1. Extract yields and extract fractions from the leaves, bark, and heartwood of Melia azedarach

\begin{tabular}{lccc}
\hline \multirow{2}{*}{ Extract/fraction } & & Yield (\%) & \\
\cline { 2 - 4 } & Leaf & Bark & Heartwood \\
\hline Acetone extract & 10.53 & 7.54 & 0.74 \\
HF & 6.70 & 1.28 & 0.33 \\
DF & 2.80 & 0.69 & 0.25 \\
EF & 0.08 & 2.95 & 0.12 \\
WF & 0.95 & 2.62 & 0.04 \\
\hline
\end{tabular}

Notes: HF is hexane soluble fraction, DF is diethyl ether soluble fraction, EF is ethyl acetate soluble fraction, and WF is water soluble fraction (WF). 
The percentage yield of the fraction showed a different tendency in each section. The fraction of the leaf extract showed the highest percentage of the n-hexane fraction. The same phenomenon was also obtained from the fraction of the heartwood. The fraction of Melia azedarach bark extract showed a different trend. The ethyl acetate and water fractions showed higher yields than other fractions.

The leaf and heartwood extract of Melia azedarach probably contained higher nonpolar compounds due to the higher percentage of hexane soluble fraction yield than other fractions. It might be because $n$-hexane is a nonpolar solvent capable of dissolving nonpolar compounds (Abarca-Vargas et al. 2016). This heartwood and leaf probably contain compounds that are usually found in nonpolar fractions, such as terpenoids and limnoids (Sharma and Singla 2013; Zeng et al. 2019). In contrast to heartwood and leaf, the bark was dominated by polar compounds indicated by higher yields of ethyl acetate and water fractions. These two types of solvents are polar solvents capable of dissolving polar compounds (Abarca-Vargas et al. 2016). Our results were in line with the previous studies that succeeded in isolating flavonoid compounds from Melia azedarach bark (Sharma and Singla 2013).

\subsection{Anti-termite Properties of the Extract Fraction}

The anti-termite properties of the fraction of Melia azedarach's leaf, bark, and heartwood showed an increased mortality percentage with increasing concentration. The tendency is shown for all sections (leaf, bark, and heartwood) and all fractions (Fig. 3).
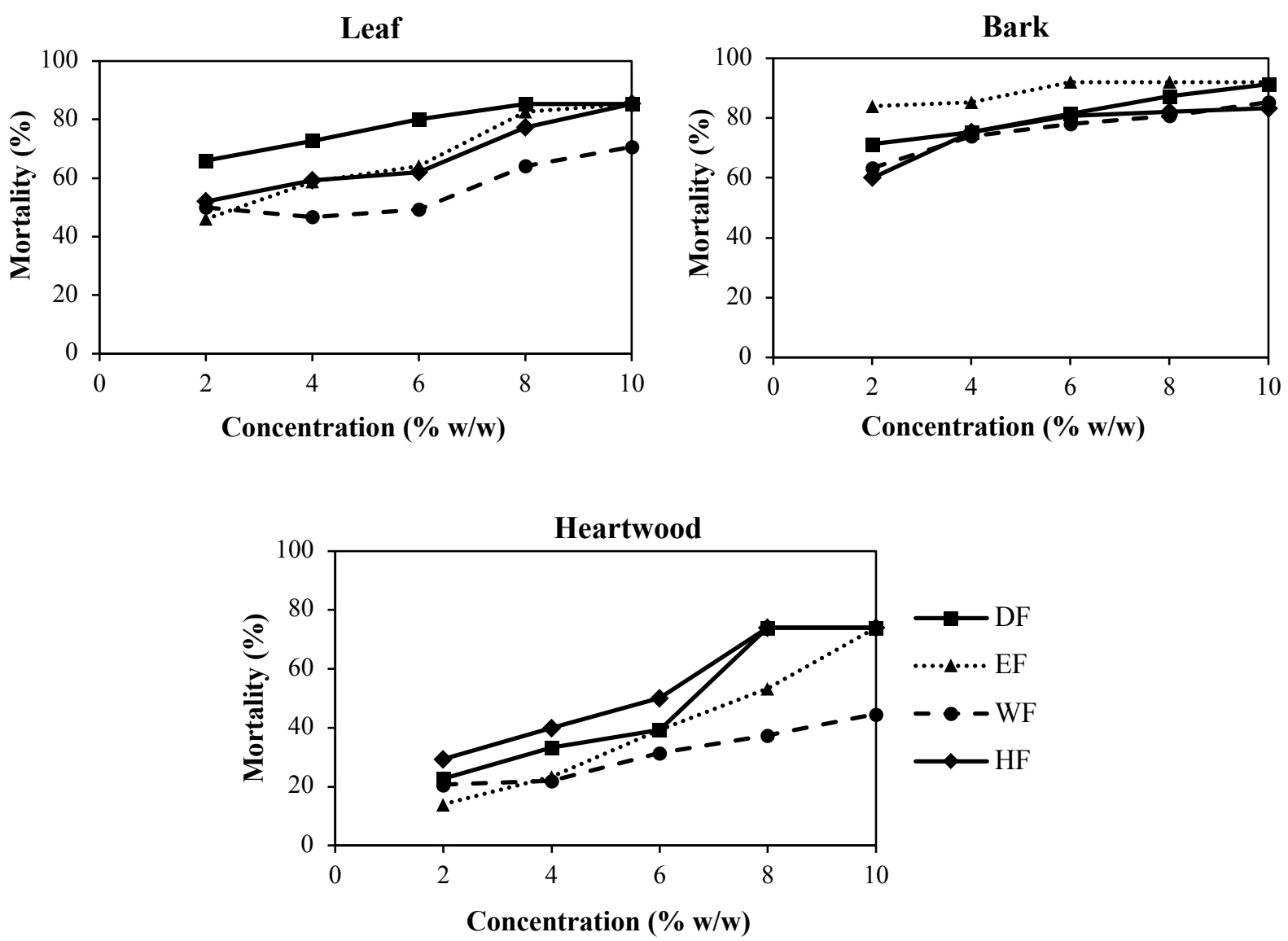

Fig. 3. The relationship between the termite mortality percentages and the test concentration. 
The percentage of deaths, in this case, indicated the toxicity of the fraction to termites. The fraction that was able to produce the highest percentage of mortality at the lowest test concentration showed the high toxicity of the fraction to termites. The DF leaf showed the highest mortality percentage at the lowest concentration compared to other leaf fractions. The highest to lowest toxicity of the Melia azedarach leaf fraction was DF, HF, AF, and EF, respectively. Different things were shown in the bark and heartwood fractions. The fractions with the highest toxicity from bark and heartwood extracts were EF and HF, respectively. Based on the mortality percentage, the fraction of leaf and bark had similarity with the mortality percentage range at the lowest concentration above 50\%. However, a different phenomenon occurred in the heartwood fraction. Only HF had a mortality percentage above $50 \%$ at the lowest concentration. Mishra et al. (2017) also reported that the mortality of Microcerotermes beesoni termite increased up to $20 \%$ as increasing the concentrations of Punica granatum fruit rind fractions.

Toxicity analysis can also be predicted based on the $\mathrm{LC}_{50}$ value, which describes the concentration at $50 \%$ mortality of the total termite individual. Based on this method, the fractions from all sections showed quite diverse toxicity to termites and were in line with the curve depiction of the concentration and mortality relationship. The $\mathrm{LC}_{50}$ value of each fraction showed high toxicity, which was less than 20\% (w/w) (Table 2). Trends in the values of leaf fractions with increased toxicity, namely the WF, EF, DF, and HF. Two types of fractions, namely the DF and HF, were more toxic than other fractions. The heartwood HF ( $\mathrm{LC}_{50} 4.62 \%$ ) also showed high toxicity compared to the other heartwood fractions. In addition, the bark fraction also showed similar toxicity to the leaves fraction. The order of bark fractions from high to low toxicity was EF, DF, WF, and HF. Likewise, Qureshi et al. (2015) also reported that Melia azedarach leaf's aqueous extract and methanol showed high toxicity values in Odontotermes obesus and Microtermes obesi termites.

Table 2. Toxicity of Melia azedarach's leaf, bark, and heartwood extract fractions

\begin{tabular}{cccc}
\hline \multirow{2}{*}{ Fraction type } & \multicolumn{3}{c}{ LC $_{\mathbf{5 0}}(\mathbf{\%}$ w/w) } \\
\cline { 2 - 4 } & Leaf & Bark & Heartwood \\
\hline HF & 0.78 & 1.01 & 4.62 \\
DF & 0.82 & 0.78 & 5.42 \\
EF & 2.63 & 0.09 & 6.84 \\
WF & 3.20 & 0.91 & 17.35 \\
\hline
\end{tabular}

Notes: HF is hexane soluble fraction, DF is diethyl ether soluble fraction, EF is ethyl acetate soluble fraction, and WF is water soluble fraction (WF).

The decrease in weight of the cellulose paper after 21 days of the experiment showed the fraction's anti-termite properties. The decrease in the weight of cellulose paper was inversely proportional to the increase in concentration (Table 3). At the highest concentration $(10 \% \mathrm{w} / \mathrm{w})$, the weight reduction percentage of cellulose paper showed the lowest value compared to other concentrations. The tendencies were shown to all types of fractions in the three extracts. The leaf DF had the lowest weight loss of cellulose paper compared to all fractions. It indicated that the leaf DF was the best fraction to prevent termites from consuming cellulose paper or had the best antifeedant activity. Increasing concentration, which causes a lower percentage of cellulose paper weight loss, was also observed in longicamphenylone and isolongifolic acid compounds (Mukai et al. 2017). 
Table 3. Percentage of weight loss of cellulose paper after 21 days of treatment

\begin{tabular}{rlrrrrr}
\hline \multirow{2}{*}{ Part/fraction type } & \multicolumn{6}{c}{ Percentage of weight loss of cellulose paper (\%) in concentration } \\
\cline { 2 - 7 } & \multicolumn{2}{c}{$\mathbf{2 \%}$} & $\mathbf{4 \%}$ & $\mathbf{6 \%}$ & $\mathbf{8 \%}$ & $\mathbf{1 0 \%}$ \\
\hline \multirow{6}{*}{ Leaf } & 42.17 & 42.17 & 42.17 & 42.17 & 42.17 \\
& Control & 23.63 & 21.45 & 13.44 & 3.43 & 3.22 \\
& HF & 11.63 & 7.99 & 5.73 & 5.37 & 0.63 \\
& DF & 26.04 & 14.77 & 12.07 & 5.61 & 1.15 \\
& EF & 24.64 & 24.64 & 22.63 & 14.22 & 14.17 \\
\hline \multirow{6}{*}{ Bark } & WF & 39.50 & 39.50 & 39.50 & 39.50 & 39.50 \\
& Control & 21.70 & 19.50 & 18.40 & 16.20 & 14.50 \\
& HF & 20.80 & 19.00 & 18.70 & 15.30 & 12.50 \\
& DF & 13.50 & 13.80 & 11.60 & 9.80 & 6.30 \\
& EF & 22.10 & 19.60 & 16.90 & 15.60 \\
\hline \multirow{6}{*}{ Heartwood } & WF & 30.36 & 30.36 & 30.36 & 30.36 \\
& Control & 30.36 & 18.54 & 16.65 & 13.50 & 12.29 \\
& HF & 21.21 & 20.56 & 19.79 & 17.34 & 15.62 \\
& DF & 23.58 & 21.43 & 20.54 & 18.59 & 17.07 \\
& EF & 24.27 & 22.80 & 20.85 & 18.30 \\
\hline
\end{tabular}

Notes: HF is hexane soluble fraction, DF is diethyl ether soluble fraction, EF is ethyl acetate soluble fraction, and WF is water soluble fraction (WF).

The anti-termite properties of the fraction can also be described in terms of the percentage of prevention of consumption (antifeedant) of cellulose paper at a concentration of $2-10 \%(\mathrm{w} / \mathrm{w})$. The percentage value of prevention was obtained by reducing the percentage of weight loss on the control cellulose paper against the fraction treatment (Fig. 4).

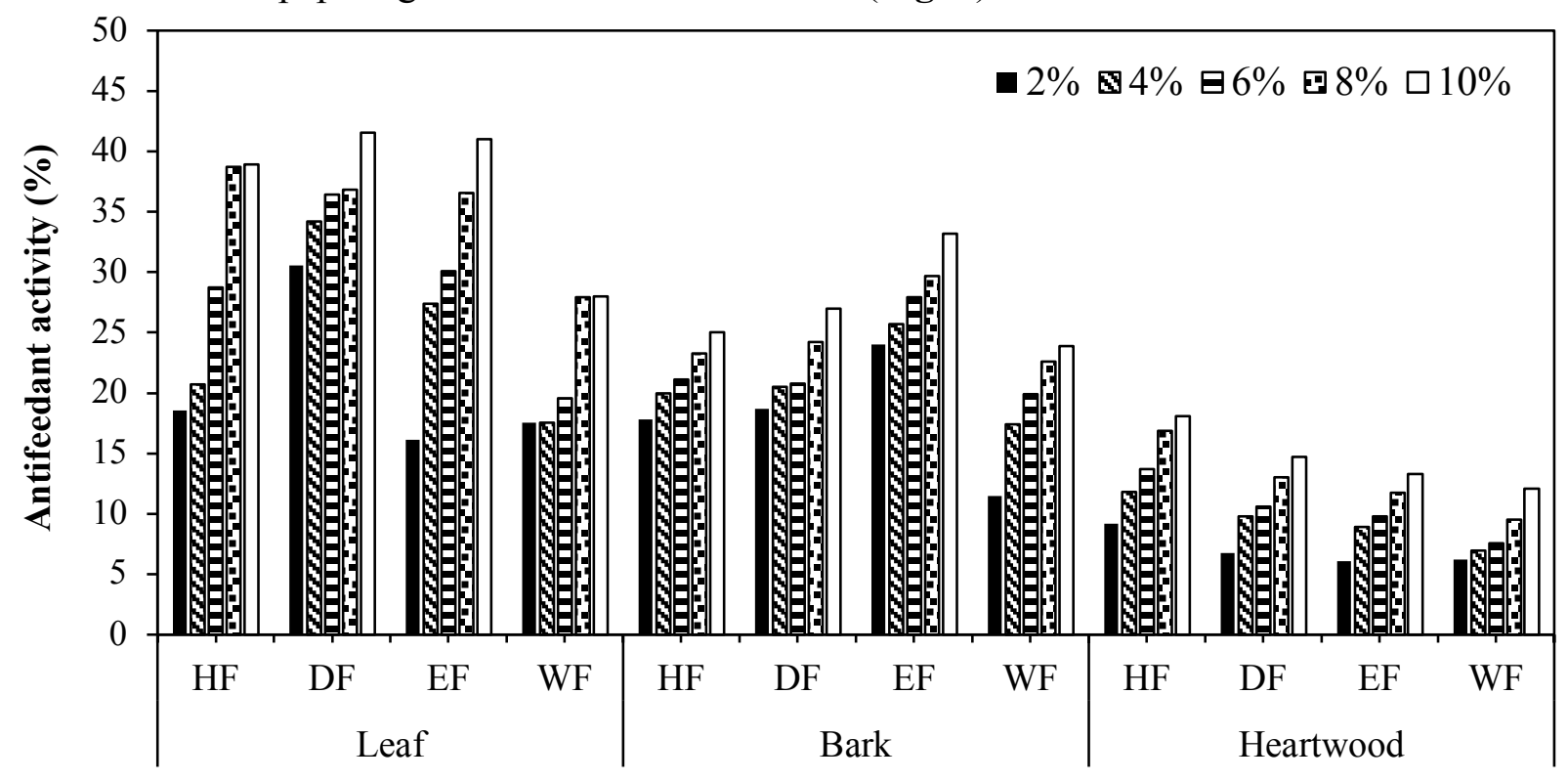

Fig. 4. Percentage of antifeedant activity to concentration in Melia azedarach's leaf, bark, and heartwood extract fractions.

The highest percentage showed that the difference in the weight loss was high between the treatment fraction and control, indicating good antifeedant properties (Fig. 4). The percentage of antifeedant shows an increasing trend which is in line with the increase in concentration. A similar 
phenomenon was also observed in the treatment effect of longifolene compounds from essential pine oil (Mukai et al. 2017). The tendency was also found in all types of Melia azedarach extract fractions. Overall, the lowest and highest antifeedant percentages were produced in $10 \%(\mathrm{w} / \mathrm{w})$ of leaf DF and 2\% (w/w) heartwood EF with 41.54\% and 6.09\%, respectively. When reviewed in each section, the trend of the lowest and highest weight loss percentages is different for each section. Leaf DF had the best antifeedant effectiveness because it had the highest antifeedant percentage (30.54\%) at the lowest concentration. Similar phenomena also showed in other parts but differed in terms of the type of fraction. The ethyl acetate and $n$-hexane soluble fractions had the highest antifeedant percentage at a concentration of $2 \%(\mathrm{w} / \mathrm{w})$ in the bark $(24 \%)$ and the heartwood $(9.15 \%)$. It also showed that these two fractions had the best effectiveness as antifeedants.

Mortality and antifeedant activity of all fractions showed a relationship that could predict the anti-termite mechanism of the best fraction in each type of extract. Based on the high mortality value and the best-antifeedant activity, the most active fractions from each part were leaf DF, bark $\mathrm{EF}$, and heartwood HF. The low mortality percentage and high antifeedant activity indicate an anti-termite mechanism in preventing consumption (antifeedant). This mechanism was observed in the leaf diethyl ether fraction because the toxicity value of the leaf diethyl ether fraction (LC50: $0.82 \% \mathrm{w} / \mathrm{w}$ ) was lower than that of the bark ethyl acetate fraction $\left(\mathrm{LC}_{50}: 0.09 \% \mathrm{w} / \mathrm{w}\right)$, but the antifeedant percentage of the bark ethyl acetate fraction was higher than the other fractions. On the other hand, the bark fraction probably contained an anti-termite mechanism through its toxicity (termicide) because the toxicity value of the bark EF was higher than that of the leaf fraction, but its antifeedant activity was lower compared with the other fractions. The anti-termite mechanism through antifeedant activity has previously been observed in norlongilactone, longifolic acid, and isolongifelic acid compounds, while a toxic mechanism with low antifeedant activity was observed in longicamphenylon compounds (Mukai et al. 2017). However, these two types of mechanisms were not observed in the heartwood extract fraction, which had low toxicity and antifeedant activity.

\subsection{Metabolite Components in the Best Fraction of Each Type of Extract}

The three fractions with the high toxicity based on mortality percentage and the bestantifeedant activity, namely leaf DF, bark EF, and heartwood HF, showed different constituents based on pyrolysis-GCMS analysis (Table 4). Leaf DF was dominated by long-chain organic acids (lipids) and short chains (cinnamic acid, benzoic acid, benzenepropanoic acid, and acetic acid). Meanwhile, bark EF was dominated by phenolic compounds with a dominance of pyrocatechol compounds. Heartwood HF was composed of nonpolar compounds with long carbon chains, namely lipids, aldehydes, steroids, and sterols. These three extracts can be arranged based on the increasing polarity, namely HF of heartwood, DF of leaves, and EF of bark if sorted by polarity.

The anti-termite properties of the three fractions were related to the composition of the compound in the fractions. As previously discussed, the three fractions could be sorted by increasing their anti-termite properties, namely bark, leaves, and heartwood (based on extract toxicity) and leaves, bark, and heartwood (based on termite activity). If it is related to the compound content of each of these fractions, qualitatively, phenolic compounds play an essential role in anti-termite properties in this study. It was shown in the bark EF, which has anti-termite properties through the toxic mechanism with a dominant and more excellent content of phenolic 
compounds than in leaf DF and heartwood HF. In addition, the acidic compounds also showed potential as anti-termite components through the antifeedant mechanism, which was responsible for the anti-termite properties of the leaf DF, especially carboxylic acids with benzene and lipid structures. Compound with long-chain carbon also showed a similar effect as shown in heartwood HF. Consequently, it revealed that the constituents that play an essential role in the anti-termite properties of the Melia azedarach tree fraction are compounds with phenolic structure, a carboxylic acid group, and a long-chain carbon. Adfa et al. (2010) also explained that flavonoid and coumarin compounds have good anti-termite properties.

Table 4. Metabolite constituents from leaf DF, bark EF, and heartwood HF

\begin{tabular}{lcccc}
\hline \multirow{2}{*}{ Compounds name } & \multicolumn{3}{c}{ Abundance (\%) } & Group of \\
\cline { 2 - 4 } & Leaf & Bark & Heartwood & compounds \\
\hline Cinnamic acid & 18.54 & - & 0.30 & Organic acid \\
Benzoic acid & 12.82 & - & 1.38 & Organic acid \\
Benzenepropanoic acid & 9.07 & - & 0.53 & Organic acid \\
Acetic acid & - & 7.49 & - & Organic acid \\
Palmitic acid & 4.98 & 3.83 & 13.10 & Lipids \\
Stearic acid & 1.78 & - & - & Lipids \\
Lauric acid & 2.01 & - & 1.42 & Lipids \\
Myristic acid & 1.48 & 0.80 & 0.71 & Lipids \\
Fitol & 4.01 & - & - & Phenolic \\
p-cresol & 1.69 & - & - & Phenolic \\
Carvacrol & 1.58 & - & - & Phenolic \\
Pyrocatechol & - & 10.39 & - & Phenolic \\
4-methylcatechol & - & 5.00 & - & Phenolic \\
Guaiacol & - & 1.40 & 0.32 & Phenolic \\
o-ethylphenol & - & 0.30 & - & Phenolic \\
2-methoxy-4-methylphenol & - & 0.44 & - & Phenolic \\
P-Ethyl guaiacol & - & 1.10 & - & Phenolic \\
2,6-dimethoxyphenol & - & 1.28 & - & Phenolic \\
p-benzyl-phenol & - & 2.03 & - & Phenolic \\
Dioctyl Phthalate & - & 4.37 & - & Esther \\
Sitosterol & - & 3.26 & - & Steroids \\
18-Hydroxydeoxycorticosterone & - & - & 3.45 & Steroids \\
Limonene & - & - & 0.65 & Terpenoids \\
Alpha-Cadinol & - & - & 2.39 & Terpenoids \\
Cis-9-Octadecenal & - & - & 19.71 & Aldehyde \\
Octadecanal & - & - & 7.88 & Aldehyde \\
17beta-Methyl-5alpha-androstan-16-one & - & - & 11.78 & Steroids \\
\hline & & & &
\end{tabular}

\section{Conclusions}

The best fractions from the leaves, bark, and heartwood were the leaf diethyl ether, bark ethyl acetate, and heartwood hexane fractions, respectively. The ethyl acetate fraction of Melia azedarach bark showed a toxic anti-termite mechanism, while the diethyl ether fraction showed an anti-termite mechanism through antifeedant activity. The hexane fraction of heartwood had weaker termite-resistant properties than the leaf and bark fraction. Components of organic acids (simple, aromatic, and long-chain), phenolic compounds, steroids, and terpenoids affected the bioactivity. Based on these results, the fraction of Melia azedarach leaf, bark, and heartwood acetone extract can be developed as an active ingredient of termite biopesticide. 


\section{Acknowledgments}

This research is partly supported by the Ministry of Education and Culture of Indonesia through the Pendidikan Magister menuju Doktor untuk Sarjana Unggul program.

\section{References}

Abarca-Vargas, R., Peña Malacara, C. F., and Petricevich, V. L. 2016. Characterization of Chemical Compounds with Antioxidant and Cytotoxic Activities in Bougainvillea $x$ Buttiana Holttum and Standl, (Var. rose) Extracts. Antioxidants 5(4): 45. DOI: 10.3390/antiox5040045

Adedeji, G. A., Ogunsanwo, O. Y., and Elufioye, T. O. 2017. Quantifications of Phytochemicals and Biocide Actions of Lawsonia inermis Linn. Extracts Against Wood Termites and Fungi. International Biodeterioration and Biodegradation 116: 155-162. DOI: 10.1016/j.ibiod.2016.10.026

Adfa, M., Yoshimura, T., Komura, K., and Koketsu, M. 2010. Antitermite Activities of Coumarin Derivatives and Scopoletin from Protium javanicum Burm. f. Journal of Chemical Ecology 36(7): 720-726. DOI: 10.1007/s10886-010-9807-1

Al-Mehmadi, R. M., and Al-Khalaf, A. A. 2010. Larvicidal and Histological Effects of Melia azedarach Extract on Culex quinquefasciatus Say Larvae (Diptera: Culicidae). Journal of King Saud University - Science 22(2): 77-85. DOI: 10.1016/j.jksus.2010.02.004

Bédounguindzi, W. F., Candelier, K., Edou Engonga, P., Dumarçay, S., Thévenon, M.-F., and Gérardin, P. 2020. Anti-Termite and Anti-Fungal Bio-Sourced Wood Preservation Ingredients from Dacryodes edulis (G. Don) H.J. Lam Resin. Holzforschung 74(8): 745-753. DOI: $10.1515 / \mathrm{hf}-2019-0106$

Cavoski, I., Chami, Z., Bouzebboudja, F., Sasanelli, N., Simeone, V., Mondelli, D., Miano, T., Sarais, G., Ntalli, N. G., and Caboni, P. 2012. Melia azedarach Controls Meloidogyne incognita and Triggers Plant Defense Mechanisms on Cucumber. Crop Protection 35: 8590. DOI: 10.1016/j.cropro.2012.01.011

Defagó, M. T., Dumón, A., Avalos, D. S., Palacios, S. M., and Valladares, G. 2011. Effects of Melia azedarach Extract on Cotesia ayerza, Parasitoid of the Alfalfa Defoliator Colias Lesbia. Biological Control 57(2): 75-78. DOI: 10.1016/j.biocontrol.2011.01.002

Finney, D. J., and Stevens, W. L. 1948. A Table for the Calculation of Working Probits and Weights in Probit Analysis. Biometrika 35(1/2): 191. DOI: 10.2307/2332639

Łebkowska, M., Załeska-Radziwiłł, M., Rutkowska-Narozniak, A., and Kobiela, S. 2003. Toxicity Assessment of Wood Preservatives. Environment International 28(8): 801-802. DOI: 10.1016/s0160-4120(02)00113-7

Maranhão, C. A., Pinheiro, I. O., Santana, A. L. B. D., Oliveira, L. S., Nascimento, M. S., and Bieber, L. W. 2013. Antitermitic and Antioxidant Activities of Heartwood Extracts and Main Flavonoids of Hymenaea stigonocarpa Mart. International Biodeterioration and Biodegradation 79: 9-13. DOI: 10.1016/j.ibiod.2013.01.005

Mishra, T., Pal, M., Kumar, A., Rai, D., and Tewari, S. K. 2017. Termiticidal Activity of Punica granatum fruit Rind Fractions and Its Compounds Against Microcerotermes beesoni. Industrial Crops and Products 107: 320-325. DOI: 10.1016/j.indcrop.2017.05.030 
Mukai, A., Takahashi, K., and Ashitani, T. 2017. Natural Autoxidation of Longifolene and AntiTermite Activities of the Products. Journal of Wood Science 63(4): 360-368. DOI: 10.1007/s10086-017-1637-0

Nandika, D., Rismayadi, Y., and Diba, F. 2003. Rayap: Biologi dan Pengendaliannya. Muhammadiyah University Press. Surakarta, Indonesia.

Nandika, D. 2015. Satu Abad Perang Melawan Rayap. Presented in Workshop Mitigasi Bahaya Serangan Rayap pada Bangunan Gedung. Hotel Santika Taman Mini Indonesia Indah Jakarta. 16 April 2015.

Nathan, S. S., and Sehoon, K. 2006. Effects of Melia azedarach L. Extract on the Teak Defoliator Hyblaea puera Cramer (Lepidoptera: Hyblaeidae). Crop Protection 25(3): 287-291. DOI: 10.1016/j.cropro.2005.03.023

Qureshi, N. A., Ashraf, A., Afzal, M., and Ullah, N. 2015. Toxic Potential of Melia azedarach Leaves Extract Against Odontotermes obesus and Microtermes obesi. International Journal of Biosciences 6(2): 120-127. DOI: 10.12692/ijb/6.2.120-127

Statistics Indonesia (BPS). 2019. Statistik Produksi Kehutanan 2019. Jakarta (ID).

Wang, Z., Liu, Y., Li, T., Zhang, Q., Bai, H., Cai, Y., and Lv, Q. 2021. Wood Preservatives in Children's Wooden Toys from China: Distribution, Migration, Oral Exposure, and Risk Assessment. Ecotoxicology and Environmental Safety. 209: 111786. DOI: 10.1016/j.ecoenv.2020.111786

Zeng, J., Ma, R. J., Wang, L., Zhang, S. N., Song, H. Z., Yang, Y., and Tan, Q. G. 2019. Chemical Constituents from the Leaves of Melia azedarach. Natural Product Research 33(19): 28602863. DOI:10.1080/14786419.2018.1501690 